\title{
TACKLING EXTREME POVERTY THROUGH PSYCHOLOGICAL SUPPORT IN BANGLADESH
}

In the last 20 years, remarkable progress has been made in tackling extreme poverty. Yet, while the number of people living on less than US\$1.90 per day in 2015 was 736 million (10 per cent of the global population, down from 11 per cent in 2013), the rate of poverty reduction has started to decline. Reaching and keeping the most vulnerable and marginalised people out of poverty is harder than ever. A novel initiative in Bangladesh, led by the international non-governmental organisation BRAC, to provide material and psychological support to the poorest individuals and households has proved to be a sustainable and lasting way to prevent them from falling back into poverty.

\section{THE CHALLENGE}

Microfinance initiatives (MFIs) are widely used by governments and non-governmental organisations to help the poor to their way out of desperate poverty and to provide a reliable and safe source of income. Yet, in the early 1990s, the international non-governmental organisation BRAC recognised that MFIs are not always an appropriate way to support the extreme poor as they fail to take into account the psychological, cultural, and physical barriers that prevent people from setting up and maintaining their own small businesses.

Women in particular can often be excluded and isolated in a male-dominated society, and lack the networks and connections required for support and to effectively use the loan successfully.

\section{THE RESEARCH}

Through BRAC's Challenging the Frontiers of Poverty Reduction: Targeting the Ultra-Poor (CFPR-TUP) programme, over 650,000 ultra-poor families have graduated out of ultra or extreme poverty since 2002. This programme worked on the logic that those living in

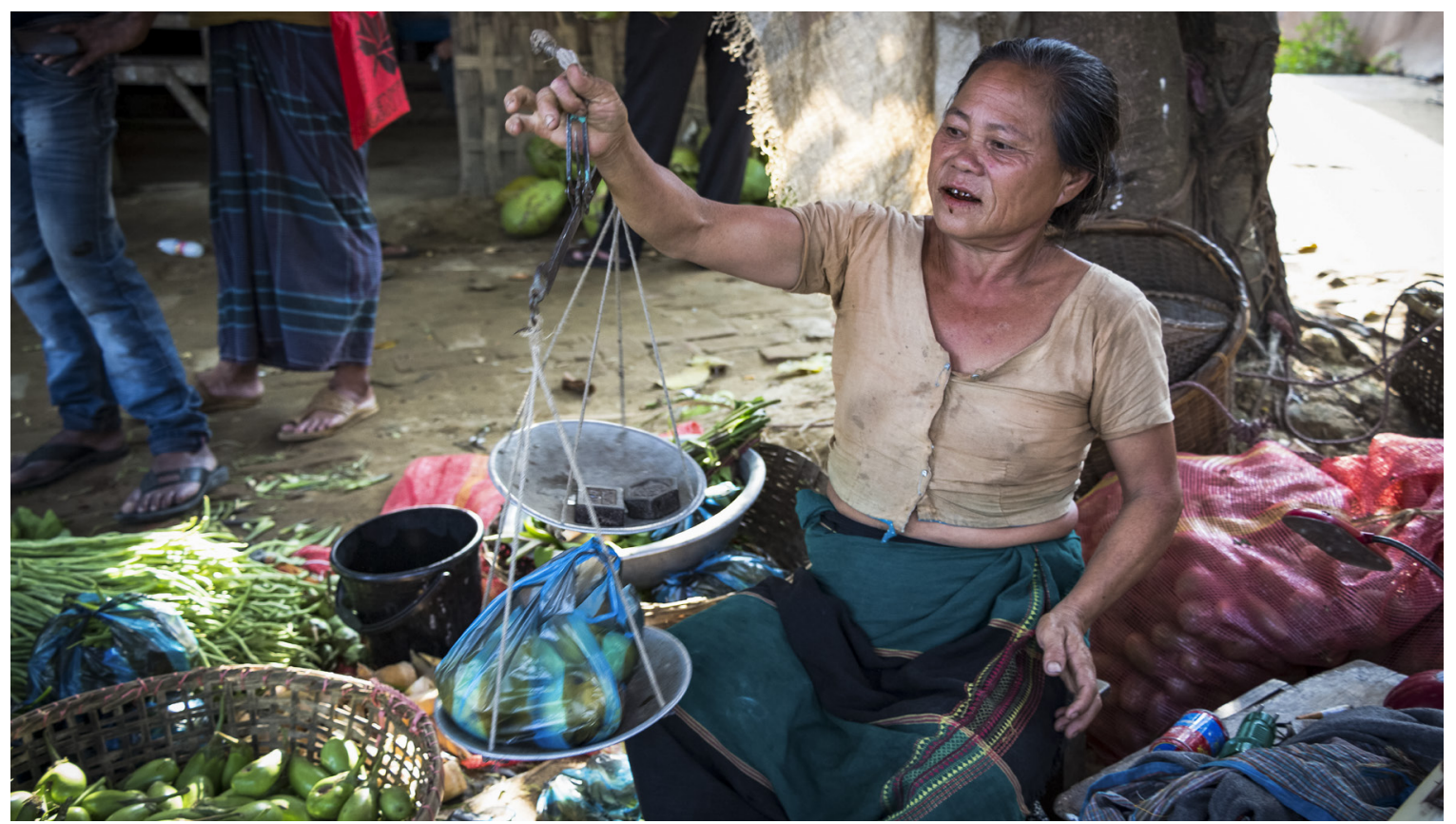

Cover photo: Measuring vegetables while selling in the market at Khagrachari, Bangladesh. Credit: (c) IFPRI/Farha Khan, licensed unde CC BY-NC-ND 2.0. 
extreme poverty needed some kind of 'asset transfer'. Since most participants were illiterate they required training to take care of their 'business' assets - i.e. a cow, a flock of chickens, or a small grocery shop. That logic extended to the understanding that in order to benefit from having these assets the families have to be well looked after. Each family was provided with a case worker who gave not only practical guidance but also emotional support.

The ESRC-DFID Joint Fund for Poverty Alleviation Research funded the Graduation as Resilience programme through two stages from 2013 to 2018 to understand what aspects of BRAC's already successful CFPR-TUP programme could be replicated. In the first stage, researchers adopted a model of psychological wellbeing instrument and used it on a sample of women from the CFPR-TUP to find out how well they could manage specific tasks, such as looking after their assets, and the level and type of support they had received to enable them to do so.

The second phase of the programme tested the new 'psychosocial' model in three programmes in Bangladesh to see if it worked on a broader scale - it included one BRAC programme (CFPR-TUP) and two government-supported programmes carried out by Palli Karma-Sahayak Foundation (PKSF). The research asked 1,800 households across the programmes about what aspects helped people get out of poverty and showed overwhelmingly that the case-by-case support was pivotal in achieving that.

\section{THE IMPACT}

The assessment of the CFPR-TUP and roll-out of the model showed that the success of the CFPR-TUP was not an isolated example. Ninety-five per cent of participants in phase 2 of the research graduated out of ultra or extreme poverty in Bangladesh. The UK government's Department for International Development (DFID), Australia's Department of Foreign Affairs and Trade, and others continue to fund this programme.

Based on the evidence, DFID encouraged other organisations to take up the approach and funded other major programmes in Bangladesh based on the same model. The model was copied globally with support from the Consultative Group to Assist the Poor (CGAP), the Ford Foundation, and other donors.

A major research study, published in Science Magazine, produced compelling evidence of the success of 'Graduation' pilot projects in Ethiopia, Ghana, Honduras, India, Pakistan and Peru, and the approach is now being promoted globally by the World Bank and other major international development actors. As the evaluator of the CGAP and Ford Foundation-funded six-country programmes concluded, 'a multifaceted approach to increasing income and wellbeing for the ultra-poor [the BRAC programme] is sustainable and cost-effective'.

The Graduation as Resilience research has shown overwhelmingly the success of incorporating a more holistic approach to addressing extreme poverty. As the global community strives to achieve the Sustainable Development Goals by 2030, it is those in extreme poverty who remain the hardest to reach and support. By evaluating the successful BRAC programme, and working closely with the Bangladeshi government, it is evident that there are components that can be replicated elsewhere, within the country and further afield.

\section{FURTHER READING}

Banerjee, A. et al. (2015) 'A Multifaceted Program Causes Lasting Progress for the Very Poor: Evidence from Six Countries', Science 348.6236, doi:10.1126/ science.1260799 (accessed 26 October 2018)

Bandiera, O. et al. (2017) 'Labor Markets and Poverty in Village Economies', The Quarterly Journal of Economics 132.2: 811-70, doi:10.1093/q je/q jx003 (accessed 26 October 2018)

Raza, W.A.; Van de Poel, E. and Van Ourti, T. (2018) 'Impact and Spill-over Effects of an Asset Transfer Program on Child Undernutrition: Evidence from a Randomized Control Trial in Bangladesh', Journal of Health Economics 62 (November): 105-20, doi:10.1016/j.jhealeco.2018.09.011 (accessed 26 October 2018)

Mahbub, U. (2018) Can Empathy End Poverty?, BRAC blog, 25 September, http://blog.brac.net/can-empathyend-poverty/ (accessed 26 October 2018)

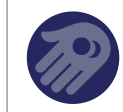

Graduation as resilience

\section{Graduation as resilience stage two}

The research team was funded by ESRC-DFID's Joint Fund for Poverty Alleviation Research, led by Mushtaque Chowdhury, BRAC, Bangladesh. It is a collaborative project involving BRAC, IDS, and PKSF.

\section{THE IMPACT INITIATIVE}

\section{For International Development Research}

The Impact Initiative seeks to connect policymakers and practitioners with the world-class social science research supported by the ESRC-DFID Strategic Partnership, maximising the uptake and impact of research from: (i) the Joint Fund for Poverty Alleviation Research, and (ii) the Raising Learning Outcomes in Education Systems Programme. We seek to identify synergies between these programmes and their grant holders, support them to exploit influencing and engagement opportunities, and facilitate mutual learning. The Impact Initiative is a collaboration between the Institute of Development Studies (IDS) and the University of Cambridge's Research for Equitable Access and Learning (REAL) Centre.

All content is available under the Open Government License v3.0, except where otherwise stated.

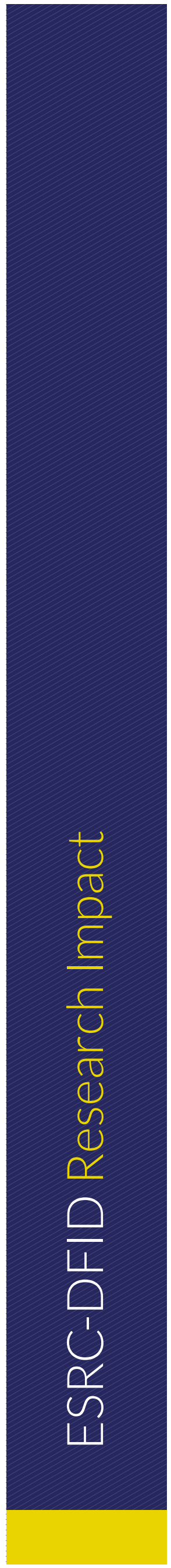

